\title{
An investigation on hygroscopic properties of 15 black carbon (BC)-containing particles from different carbon sources: roles of organic and inorganic components
}

\author{
Minli Wang ${ }^{1}$, Yiqun Chen ${ }^{1}$, Heyun Fu' ${ }^{1}$, Xiaolei Qu ${ }^{1}$, Bengang $\mathrm{Li}^{2}$, Shu Tao ${ }^{2}$, and Dongqiang $\mathrm{Zhu}^{1,2}$ \\ ${ }^{1}$ State Key Laboratory of Pollution Control and Resource Reuse, School of the Environment, \\ Nanjing University, Jiangsu 210046, China \\ ${ }^{2}$ School of Urban and Environmental Sciences, Key Laboratory of the Ministry of Education for Earth Surface Processes, \\ Peking University, Beijing 100871, China
}

Correspondence: Dongqiang Zhu (zhud@pku.edu.cn)

Received: 8 February 2020 - Discussion started: 27 February 2020

Revised: 23 May 2020 - Accepted: 16 June 2020 - Published: 8 July 2020

\begin{abstract}
The hygroscopic behavior of black carbon (BC)containing particles (BCPs) has a significant impact on global and regional climate change. However, the mechanism and factors controlling the hygroscopicity of BCPs from different carbon sources are not well understood. Here, we systematically measured the equilibrium and kinetics of water uptake by 15 different BCPs (10 herb-derived BCPs, 2 woodderived BCPs, and 3 soot-type BCPs) using a gravimetric water vapor sorption method combined with in situ diffuse reflectance infrared Fourier transform spectroscopy (DRIFTS). In the gravimetric analysis, the sorption-desorption equilibrium isotherms were measured under continuous-stepwise water vapor pressure conditions, while the kinetics was measured at a variety of humidity levels obtained by different saturated aqueous salt solutions. The equilibrium water uptake of the tested group of BCPs at high relative humidity $(>80 \%)$ positively correlated to the dissolved mineral content $(0.01-13.0 \mathrm{wt} \%)\left(R^{2}=0.86, P=0.0001\right)$, the content of the thermogravimetrically analyzed organic carbon (OC $\mathrm{TGA}, 4.48-15.25 \mathrm{wt} \%)\left(R^{2}=0.52, P=0.002\right)$, and the content of the alkali-extracted organic carbon $\left(\mathrm{OC}_{\mathrm{AE}}, 0.14\right.$ 8.39 wt $\%)\left(R^{2}=0.80, P=0.0001\right)$. In contrast, no positive correlation was obtained with the content of total organic carbon or elemental carbon. Among the major soluble ionic constituents, chloride and ammonium were each correlated with the equilibrium water uptake at high relative humidity. Compared with the herbal BCPs and soot, the woody BCPs had much lower equilibrium water uptake, especially at high rel-
\end{abstract}

ative humidity, likely due to the very low dissolved mineral content and OC content. The DRIFTS analysis provided generally consistent results at low relative humidity. The kinetics of water uptake (measured by pseudo-second-order rate constant) correlated to the content of $\mathrm{OC}_{\mathrm{TGA}}$ and $\mathrm{OC}_{\mathrm{AE}}$ as well as the content of chloride and ammonium at low relative humidity $(33 \%)$ but to the porosity of BCPs at high relative humidity (94\%). This was the first study to show that BCPs of different types and sources had greatly varying hygroscopic properties.

\section{Introduction}

Black carbon (BC) refers to a collective term of refractory and insoluble aggregates of small carbon spherules generated from incomplete combustion of biomass and fossil fuels (Bond et al., 2013). BC-containing particles (BCPs) are ubiquitous in the atmosphere and are a major component of atmospheric carbonaceous aerosols (Schwarz et al., 2008). Due to the strong ability to absorb visible light (Yuan et al., 2016), BCPs cause positive radiative forcing effects on climate and are considered an important factor driving global warming (Matthews et al., 2009). Once immersed into cloud droplets, BCPs can also facilitate water evaporation and cloud dispersion via enhanced absorption of solar radiation and thus produce indirect radiative forcing effects (Powelson et al., 2014). Additionally, the large specific surface area of BCPs creates 
a potential for heterogeneous reactions with trace gases (such as volatile halocarbons) in the atmosphere (Qiu et al., 2012), thus heavily impacting atmospheric chemistry and air quality. Hygroscopicity is a key determinant of physical, chemical, and optical properties of BCPs by changing particle size, phase state, and quality and morphological development, which in turn affect aerosol radiation effect, formation of cloud and ice nuclei, and heterogeneous chemical reactions (Bond et al., 2013; Liu et al., 2018). Furthermore, the hygroscopicity of BCPs is an important factor contributing to the risk of human respiratory infections, cardiovascular diseases, and other infectious diseases (Haddrell et al., 2015).

Inherited from a parent carbon source or produced from combustion process, a large content of inorganic impurities are often present in BCPs, consisting of a variety of amorphous or crystalline salts (sulfates, chlorides, etc.) as well as semicrystalline minerals (such as silica) (Stanislav et al., 2013). Despite the relatively low content, the inorganic components in BCPs play a significant role in water uptake, depending on their types, contents, and mixing ratios (Lewis et al., 2009). As the factors and processes governing the hygroscopic deliquescence of inorganic salts are very complicated (Reid et al., 2005; Zhang et al., 2012), it is a great challenge to assess the contribution of a specific salt to the overall hygroscopicity of BCPs, and thus its role is still controversial. Previous studies suggested that $\mathrm{KCl}$ was responsible for the high hygroscopicity of BCPs produced by fresh biomass burning (Posfai et al., 2003), while the presence of $\mathrm{K}_{2} \mathrm{SO}_{4}$ or $\mathrm{KNO}_{3}$ caused the low hygroscopicity of BCPs produced by aged biomass burning (Li et al., 2003).

The organic components in BCPs consist of graphitized elemental carbon (EC) and non-condensed, amorphous organic carbon (OC) (Lian and Xing, 2017). The contribution of EC to the overall hygroscopicity of BCPs is considered low due to the very high hydrophobicity (Seisel et al., 2005). The role of OC in the hygroscopic growth of BCPs is intricate and debatable. The positive effect of OC is mainly attributed to water absorption by the oxygen-containing functional groups (Fletcher et al., 2007; Suda et al., 2014). The negative effect of OC is suggested to stem from the impeded mass transfer process of water molecules by formation of coatings on hygroscopic minerals or inhomogeneous morphology inside the particle (Sjogren et al., 2007; Stemmler et al., 2008). In addition to the total content, the molecular weight, water solubility, surface tension, and type and content of functional groups of OC were all found to influence the overall hygroscopicity of BCPs. Moreover, the effect of OC on BCP hygroscopicity is further complicated by the formation of organic minerals (presumably through strong covalent bonds) (Archanjo et al., 2014; Reid et al., 2005; Zuend et al., 2011).

The carbon sources for BCPs released into the atmosphere are expected to be highly diversified and cover a wide range of plant biomass, coals, and refined oil products, although their quota can hardly be accurately assessed (Andreae and Gelencser, 2006). The chemical compositional, structural, and morphological properties of BCPs depend significantly on carbon sources and combustion conditions (Xiao et al., 2018). For instance, crop-residue-derived biochar often has higher mineral content than wood-derived charcoal, while biochar formed at higher pyrolysis temperatures generally have higher aromaticity, specific surface area, and pore volume but lower polarity than biochar formed at lower temperatures (Wei et al., 2019). Compared with char and charcoal, soot (another type of BCPs) produced from fossil fuel combustion is comprised of more regular shaped, chain-like agglomerates of primary particles, which consist of perturbed graphitic layers oriented concentrically in an onion-like fashion (Nienow and Roberts, 2006). Previous studies on hygroscopicity of BCPs have mainly focused on wood-derived BCPs (Carrico et al., 2010; Day et al., 2006), whereas BCPs from other carbon sources have been largely overlooked. It remains unclear whether BCPs from different carbon sources would differ significantly in hygroscopicity.

Herein we systematically investigated the equilibrium and kinetics of water uptake by 15 different BCPs derived from wood, herb, coal, and diesel at varying relative humidity (RH) levels by gravimetric sorption and in situ diffuse reflectance infrared Fourier transform spectroscopy (DRIFTS). The chemical, compositional, and structural properties of the tested group of BCPs were thoroughly characterized to unveil the key factors controlling the hygroscopic properties.

\section{Experimental methods}

\subsection{Preparation of BCPs}

A total of 15 BCPs were tested, including 10 herb-derived BCPs, 2 wood-derived BCPs, and three soot-type BCPs. The herbs used for preparation of herbal BCPs were amaranth, peanuts, pea, grass, rice, wheat, corn, millet, sorghum (Nantong, Jiangsu Province, China), and bamboo (Lishui, Zhejiang Province, China), and the wood used for preparation of woody BCPs were red pine and poplar (Lishui, Zhejiang Province, China). The dried and dehydrated biomass was pulverized into a fine powder using a high-speed pulverizer (FW 100, Tianjin Taisite Instrument Co., China) and pyrolyzed in a muffle furnace under oxygen-limited conditions. The oven temperature was programmed to increase from 20 to $400^{\circ} \mathrm{C}$ in $2 \mathrm{~h}$ and maintained at $400^{\circ} \mathrm{C}$ for $3 \mathrm{~h}$. The Weifu diesel soot was purchased from Wuxi Weifu Automotive Diesel System Co., Ltd. (Jiangsu Province, China). According to the information provided by the manufacturer, the soot was produced under laboratory conditions by burning diesel (Diesel \#5, China) at $1000^{\circ} \mathrm{C}$ and was collected by a diesel particulate filter (NGK-6000YE) from the exhaust stream at a carbon deposition temperature of $250^{\circ} \mathrm{C}$. The diesel engine soot was collected in outdoor conditions from the freshly discharged exhaust particles on the tailpipe of a diesel truck (Dongfeng, CY4100, 2015, China) equipped 
with a diesel engine (CY4100Q, 3.7 L, Diesel \#0) and a diesel particulate filter (BST-5L-QCD). The household soot was collected on the inner wall of a stove chamber (Linkou County, Heilongjiang Province, China) $1 \mathrm{~h}$ later after burning of coal and wood for winter cooking and heating under limited oxygen exposure. The obtained samples of BCPs were further ground to pass a 100 -mesh sieve $(0.15 \mathrm{~mm})$ and stored sealed in a brown glass bottle at $4{ }^{\circ} \mathrm{C}$.

\subsection{Characterization of BCPs}

Elemental analysis (EA) was performed using a Vario micro cube elemental analyzer (Elementar, Hanau, Germany). Surface elemental compositions were measured by X-ray photoelectron spectroscopy (XPS) (PHI 5000 VersaProbe, UlVAC-PHI, Japan). Mineral compositions were measured by X-ray fluorescence (XRF) (ARL-9800, ARL Corporation, Switzerland). Fourier-transform infrared (FTIR) spectra were recorded on a Bruker Tensor 27 Karlsruhe spectrometer (Germany) using $\mathrm{KBr}$ pellets in the range of 400 to $4000 \mathrm{~cm}^{-1}$. X-ray diffraction (XRD) spectra were recorded on an AXS D8 Advance spectrometer (Germany) using $\mathrm{Cu}$ $\mathrm{K} \alpha$ radiation at a $2 \theta$ angle ranging from 5 to $70^{\circ}$. Raman spectra were collected on a Horiba Jobin Yvon LabRam HR800 spectrometer equipped with a $514 \mathrm{~nm}$ laser (France). $\mathrm{N}_{2}$ adsorption isotherms to the $15 \mathrm{BCPs}$ were obtained on a Micrometrics ASAP 2020 (Micromeritics Instrument Co., Norcross, GA, USA) apparatus at $-196^{\circ} \mathrm{C}(77 \mathrm{~K})$.

Three different methods, thermogravimetric analysis (TGA), alkali extraction, and water extraction, were explored to quantify the content of $\mathrm{OC}$ in $\mathrm{BCPs}$ (referred to as $\mathrm{OC}_{\mathrm{TGA}}$, $\mathrm{OC}_{\mathrm{AE}}$, and $\mathrm{OC}_{\mathrm{WE}}$, respectively). The content of $\mathrm{OC}_{\mathrm{TGA}}$ was measured as the weight loss during the heating of BCPs from 30 to $300^{\circ} \mathrm{C}$ at a ramp of $10^{\circ} \mathrm{C} \mathrm{min}^{-1}$ in a nitrogen flow (Han et al., 2013) using a TGA 8000 analyzer (PerkinElmer, USA). To measure the content of $\mathrm{OC}_{\mathrm{AE}}$, the sample of $\mathrm{BCPs}$ was mixed with $0.1 \mathrm{M} \mathrm{NaOH}$ at a solid-to-solution ratio of $1: 10(w / w)$ and magnetically stirred for $12 \mathrm{~h}$, followed by filtration through a $0.45 \mu \mathrm{m}$ filter membrane (Pall, USA) (Song et al., 2002). The filtrate was collected and acidified $(\mathrm{pH} 1.0$ with $6 \mathrm{M} \mathrm{HCl})$, and the total organic carbon (TOC) content of the sample was measured by a TOC analyzer (TOC-5000A, Shimadzu, Japan). For the three selected BCPs (grass, wheat, and household soot), the precipitates formed by acidification were further separated by centrifugation and dialyzed in deionized (DI) water by dialysis bag (500 Da, Union Carbide, USA) until no chloride ion was detected by $\mathrm{AgNO}_{3}$; then it was freeze-dried. The elemental compositions of the three prepared $\mathrm{OC}_{\mathrm{AE}}$ were measured by $\mathrm{EA}$. To measure the content of $\mathrm{OC}_{\mathrm{WE}}$ and dissolved minerals, the suspended BCPs in DI water (BCPs-to-water ratio of 1 : $10 \mathrm{w} / \mathrm{w}$ ) was sonicated in a water bath for several minutes, and the mixture was filtered through a $0.45 \mu \mathrm{m}$ membrane. The suspension and sonication procedure was repeated six times. The filtrate was collected and subjected to TOC anal- ysis to obtain the content of $\mathrm{OC}_{\mathrm{WE}}$. The concentrations of ionic constituents $\left(\mathrm{Cl}^{-}, \mathrm{NO}_{3}^{-}, \mathrm{PO}_{4}^{3-}, \mathrm{SO}_{4}^{2-}, \mathrm{F}^{-}, \mathrm{COO}^{-}\right.$, $\mathrm{C}_{2} \mathrm{O}_{4}^{2-}, \mathrm{Na}^{+}, \mathrm{NH}_{4}^{+}, \mathrm{K}^{+}, \mathrm{Mg}^{2+}, \mathrm{Ca}^{2+}, \mathrm{Al}^{3+}$ ) in the filtrate were measured using a Dionex ICS-1100 ion chromatograph (Thermo Scientific, USA). The cations were eluted using $20 \mathrm{mM}$ methanesulfonic acid on a Dionex IonPac CS12A column $(4 \mathrm{~mm} \times 250 \mathrm{~mm})$, while the anions were eluted using an eluent of $4.5 \mathrm{mM} \mathrm{Na}_{2} \mathrm{CO}_{3}$ and $0.81 \mathrm{mM} \mathrm{NaHCO}_{3}$ on a Dionex IonPac AS14A column $(4 \mathrm{~mm} \times 250 \mathrm{~mm})$. The filtrate was further freeze-dried and baked at $600{ }^{\circ} \mathrm{C}$ for $6 \mathrm{~h}$ to remove organic components. The remaining ash was weighed to determine the content of dissolved minerals in BCPs. A portion of the ash was extracted three times using DI water at a solid-to-solution ratio of $1: 10(w / w)$ under sonication, and the salinity of the extract was measured by a ST3100C conductivity meter (OHAUS, USA). All reagents and chemicals used were of analytical reagent grade.

\subsection{Measurement of hygroscopicity of BCPs}

The hygroscopicity of BCPs at varying RH was measured by a gravimetric method combined with in situ DRIFTS. The water vapor sorption-desorption isotherms to BCPs under a range of continuous-stepwise water vapor pressures were acquired on a $3 \mathrm{H}-2000 \mathrm{PW}$ multistation gravimetric-method steam adsorption instrument (Beijing, China) at $25^{\circ} \mathrm{C}$ using an approach similar to that in previous studies (Gu et al., 2017). The instrument consists of two main parts: a balance chamber to determine the sample mass to an accuracy $\pm 1 \mu \mathrm{g}$ and a humidity chamber to regulate the water vapor pressure to the desired value as monitored online by a pressure sensor. Prior to testing, the BCPs (about $10 \mathrm{mg}$ ) were dried at $70{ }^{\circ} \mathrm{C}$ under vacuum for $12 \mathrm{~h}$ to remove residual water vapor and set a baseline for comparison of water vapor adsorption behaviors among different samples. The amount of water sorbed to BCPs was monitored as the mass difference before and after sorption. The amount of water sorbed to the sample tube was measured and showed to be negligible $(<0.05 \%$ of the amount of water sorbed to BCPs). The water vapor pressures ranging from $10 \%$ to $94 \% \mathrm{RH}$ were applied to the sorption isotherm branch in a stepwise increasing sequence and to the desorption isotherm branch in a stepwise decreasing sequence.

The kinetics of water sorption to BCPs was measured on a $100 \mathrm{~mm}$ closed quartz chamber (Jiangsu Province, China) using a gravimetric method similar to that in previous studies (Yuan et al., 2014). Approximately $100 \mathrm{mg}$ of BCPs was dried at $70^{\circ} \mathrm{C}$ under vacuum for $12 \mathrm{~h}$, weighed in a $10 \mathrm{~mL}$ beaker, and placed in a chamber under controlled humidity conditions based on different saturated aqueous salt solutions according to ASTM E104-02 (2007). The saturated solutions of $\mathrm{CH}_{3} \mathrm{COOK}, \mathrm{MgCl}_{2}, \mathrm{~K}_{2} \mathrm{CO}_{3}, \mathrm{LiNO}_{3}, \mathrm{NaCl}, \mathrm{KCl}$, and $\mathrm{KNO}_{3}$ provided $\mathrm{RH}$ values of $23 \%, 33 \%, 43 \%, 47 \%$, $75 \%, 84 \%$, and $94 \%$, respectively, at $25^{\circ} \mathrm{C}$. The sample was continuously weighed and recorded over a period of time 
( $48 \mathrm{~h}$ for low humidity and $96 \mathrm{~h}$ for high humidity) to monitor the amount of sorbed water. The RH was monitored in real time using a Honeywell HIH4000 hygrometer (USA) with measurement variance of less than $5 \%$. Sorption equilibrium was reached in the late stage of the experiment as evidenced by the stabilized constant value of sample mass. In addition to kinetic data, sorption isotherms were also collected for the seven selected RH levels using the measured mass under equilibrium conditions.

Samples of BCPs equilibrated at different RH levels were characterized by in situ DRIFTS using a Bruker Tensor 27 spectrometer equipped with a high-sensitivity mercurycadmium-telluride (MCT) detector working under liquid $\mathrm{N}_{2}$ conditions and a chamber fitted with $\mathrm{ZnSe}$ windows (Harrick Scientific, USA). About $10 \mathrm{mg}$ of BCPs pre-dried at $70^{\circ} \mathrm{C}$ under vacuum for $12 \mathrm{~h}$ was transferred to the chamber which was connected to a gas feeding system. The chamber was sealed and purged with high-purity $\mathrm{N}_{2}$ at a flow rate of $100 \mathrm{~mL} \mathrm{~min}^{-1}$ for at least $3 \mathrm{~h}$ to remove pre-adsorbed gases on BCPs and to minimize the interference of environmental $\mathrm{CO}_{2}$. The humidity in the chamber was regulated by mixing high-purity $\mathrm{N}_{2}$ and saturated water vapor at $25^{\circ} \mathrm{C}$ with varying ratios and monitored in real time by a hygrometer (Vaisala HUMITTER, Australia). The sample was equilibrated with the gas mixture in the chamber for at least $30 \mathrm{~min}$ to reach sorption equilibrium based on predetermined kinetics. The spectra were acquired by co-adding and averaging a plurality of 500 scans with a resolution of $4 \mathrm{~cm}^{-1}$ (Song and Boily, 2013). The amount of water sorbed to BCPs was monitored by the integrated intensity of the $\mathrm{O}-\mathrm{H}$ stretching region from 2750 to $3660 \mathrm{~cm}^{-1}$ (Ghorai et al., 2011).

\section{Results and discussion}

\subsection{Characteristics of BCPs}

Bulk elemental compositions by EA and surface elemental compositions by XPS are summarized in Table S1. The bulk elemental compositions of all BCPs were dominated by $\mathrm{C}$ and $\mathrm{O}$, together accounting for $54 \%-96 \%$ of the total. However, the bulk $\mathrm{C}$ and $\mathrm{O}$ compositions differed significantly among the $15 \mathrm{BCPs}$, ranging from $32 \%$ to $76 \%$ for $\mathrm{C}$ and from $16 \%$ to $69 \%$ for $\mathrm{O}$. With the exception of the woody BCPs, the differences were apparent within each category of the herbal BCPs and the soot. Similarly, the surfaces of all the $15 \mathrm{BCPs}$ were dominated by $\mathrm{C}$ and $\mathrm{O}$; however, the differences of the surface $\mathrm{C}$ and $\mathrm{O}$ compositions among the $15 \mathrm{BCPs}$ were much smaller compared to the bulk $\mathrm{C}$ and $\mathrm{O}$ compositions. Besides $\mathrm{C}$ and $\mathrm{O}$, EA detected low amounts of $\mathrm{N}(<3.7 \%)$ and $\mathrm{S}(<1.8 \%)$, and XPS detected low amounts of $\mathrm{N}(<4.3 \%), \mathrm{Si}(<5.6 \%)$, and $\mathrm{S}(<0.6 \%)$. The contents of oxygen-containing groups in the $15 \mathrm{BCPs}$ were qualitatively compared by the FTIR spectra (Fig. S1). All the tested BCPs except Weifu diesel soot showed characteristic peaks of es- ters $\left(1700 \mathrm{~cm}^{-1}\right)$, ketones $\left(1613,1100 \mathrm{~cm}^{-1}\right)$, and phenols $\left(1270 \mathrm{~cm}^{-1}\right)$ (Keiluweit et al., 2010), generally with larger peak intensities observed for herbal BCPs and household soot.

Table 1 summarizes the contents of $\mathrm{OC}\left(\mathrm{OC}_{\mathrm{TGA}}, \mathrm{OC}_{\mathrm{AE}}\right.$, and $\left.\mathrm{OC}_{\mathrm{WE}}\right)$ of the $15 \mathrm{BCPs}$ by TGA, alkali extraction, and water extraction, respectively. For a given BCPs, the contents of the three types of $\mathrm{OC}$ differed pronouncedly, with an increasing order of $\mathrm{OC}_{\mathrm{WE}}<\mathrm{OC}_{\mathrm{AE}}<\mathrm{OC}_{\mathrm{TGA}}$. The $\mathrm{OC}$ content also differed within the tested group of BCPs, ranging from 0.05 to $2.24 \mathrm{wt} \%$ for $\mathrm{OC}_{\mathrm{WE}}$, from 0.14 to $8.39 \mathrm{wt} \%$ for $\mathrm{OC}_{\mathrm{AE}}$, and from 4.48 to $15.25 \mathrm{wt} \%$ for $\mathrm{OC}_{\mathrm{TGA}}$. Compared with the EC (graphitized carbon), the three types of OC are non-condensed, amorphous, and more rich in oxygencontaining functional groups, which was evidenced by the fact that the $\mathrm{OC}_{\mathrm{AE}}$ from the three selected $\mathrm{BCPs}$ (grass, wheat, and household soot) had markedly higher bulk compositions of $\mathrm{O}$ (results presented in Table S2). The EC content in $\mathrm{BCPs}$ was roughly assessed by subtracting the $\mathrm{OC}_{\mathrm{TGA}}$ content from the total organic carbon content measured by EA (results presented in Table 1). The calculated EC content negatively correlated with the $\mathrm{OC}_{\mathrm{AE}}$ content $\left(R^{2}=0.43\right.$, $P=0.0079)$ for the examined group of BCPs. This relationship was reasonable as EC was comprised of mature, thermodynamically stable graphitized carbons, while OC was comprised of the less mature and less aromatic constituents remaining after pyrolysis. Except for Weifu diesel soot, the two woody $\mathrm{BCPs}$ had the highest $\mathrm{EC}$, but the lowest $\mathrm{OC}_{\mathrm{AE}}$ and $\mathrm{OC}_{\mathrm{WE}}$ among the $15 \mathrm{BCPs}$.

The relative abundance of EC in BCPs was also assessed by Raman spectroscopy (Fig. S2). The spectra of all the tested BCPs were dominated by a D band at $1340 \mathrm{~cm}^{-1}$ and a $\mathrm{G}$ band at $1580 \mathrm{~cm}^{-1}$, which were ascribed to carbon network defects and the $E_{2 \mathrm{~g}}$ mode of the graphitized carbon, respectively (Pimenta et al., 2007). Thus, the ratio of these two bands $\left(I_{\mathrm{D}} / I_{\mathrm{G}}\right)$ was inversely proportional to the in-plane crystallite size of graphitized carbons of BCPs (Cancado et al., 2006). The $I_{\mathrm{D}} / I_{\mathrm{G}}$ ratio of the woody BCPs $(0.51-0.59)$ was less than those of the herbal BCPs $(0.88-$ 1.09 ) and the soot (0.77-1.12) (Table S3), suggesting larger sizes of graphitized carbons in the woody BCPs, which was consistent with the results of OC compositions.

The contents of dissolved minerals of the $15 \mathrm{BCPs}$ are listed in Table 1, and their salinities in water extracts are listed in Table S5. The two woody BCPs had the lowest contents of dissolved minerals and salinities, while these contents in herbal BCPs and soot were higher and varied greatly. The mineral compositions characterized by XRF are listed in Table S6. Si- and K-rich minerals were the two major inorganic constituents in the herbal BCPs and woody BCPs. Moreover, these two types of BCPs generally contained trace amounts of S-, Cl-, Ca-, P-, Mg-, Na-, Fe-, and Al-rich minerals, with lower contents observed for the woody BCPs. The three soot samples had very different mineral compositions. Household soot was dominated by $\mathrm{S}-, \mathrm{Ca}-, \mathrm{Si}-$, and $\mathrm{Cl}$-rich 
Table 1. Chemical, compositional, and pore properties of different BCPs.

\begin{tabular}{|c|c|c|c|c|c|c|c|}
\hline \multirow[t]{2}{*}{ BCPs } & \multicolumn{3}{|c|}{$\mathrm{OC}$} & \multirow{2}{*}{$\begin{array}{c}\mathrm{EC}^{\mathrm{d}} \\
(\mathrm{wt} \%)\end{array}$} & \multirow{2}{*}{$\begin{array}{r}\text { Dissolved } \\
\text { minerals }\end{array}$} & \multirow{2}{*}{$\begin{array}{r}\begin{array}{r}\text { Total } \\
\text { porosity }\end{array} \\
\left(\mathrm{m}^{3} \mathrm{~g}^{-1}\right)\end{array}$} & \multirow{2}{*}{$\begin{array}{r}\mathrm{SSA}^{\mathrm{f}} \\
\left(\mathrm{m}^{2} \mathrm{~g}^{-1}\right)\end{array}$} \\
\hline & $\begin{array}{r}\mathrm{OC}_{\mathrm{TGA}}^{\mathrm{a}} \\
(\mathrm{wt} \%)\end{array}$ & $\begin{array}{l}\mathrm{OC}_{\mathrm{AE}}^{\mathrm{b}} \\
(\mathrm{wt} \%)\end{array}$ & $\begin{array}{l}\mathrm{OC}_{\mathrm{WE}}^{\mathrm{c}} \\
(\mathrm{wt} \%)\end{array}$ & & & & \\
\hline Amaranth & 6.24 & 2.6 & 1.75 & 25.84 & 10.8 & 0.004 & 0.314 \\
\hline Grass & 7.24 & 2.37 & 1.01 & 51.56 & 4.8 & 0.008 & 5.587 \\
\hline Peanuts & 7.45 & 1.78 & 0.8 & 41.86 & 4.2 & 0.002 & 0.192 \\
\hline Pea & 9.59 & 1.98 & 0.09 & 54.48 & 3.6 & 0.005 & 4.679 \\
\hline Rice & 6.81 & 0.6 & 0.11 & 48.06 & 0.6 & 0.023 & 31.88 \\
\hline Wheat & 8.25 & 1.82 & 0.37 & 42.65 & 5.8 & 0.01 & 7.382 \\
\hline Millet & 9.41 & 1.97 & 0.93 & 32.25 & 8 & 0.023 & 8.319 \\
\hline Corn & 6.55 & 0.14 & 0.32 & 46.47 & 1.8 & 0.028 & 28.6 \\
\hline Sorghum & 9.09 & 1.12 & 0.62 & 55.26 & 4.8 & 0.001 & 0.192 \\
\hline Bamboo & 6.84 & 0.23 & 0.12 & 61.7 & 0.6 & 0.029 & 51.94 \\
\hline Red pine & 7.4 & 0.2 & 0.05 & 62.59 & 0.01 & 0.032 & 64.24 \\
\hline Poplar & 7.58 & 0.19 & 0.09 & 64.22 & 0.6 & 0.071 & 107.6 \\
\hline Diesel engine soot & 9.57 & 1.4 & 0.78 & 27.37 & 3.6 & 0.021 & 6.119 \\
\hline Weifu diesel soot & 4.48 & 0.57 & 0.13 & 71.98 & 3.4 & 0.484 & 194.6 \\
\hline Household soot & 15.25 & 8.39 & 2.24 & 21.83 & 13 & 0.012 & 7.79 \\
\hline
\end{tabular}

minerals, diesel engine soot was dominated by $\mathrm{S}-, \mathrm{Ca}-$, and Fe-rich minerals, while Weifu diesel soot contained negligible mineral compositions. As reflected by the observed characteristic peaks and associated peak intensities in the XRD spectra (Fig. S3), the herbal BCPs and household soot contained more mineral species with higher contents than other BCPs, whereas the two woody BCPs and Weifu diesel soot contained the least species and contents of minerals. Potassium salts, amorphous silica, and sulfates were the major minerals in the herbal BCPs. Soot had the largest content of sulfates among the tested BCPs. According to the ion chromatograph analysis (results presented in Fig. S4 and Table S7), the major water-extracted cationic species from the tested $\mathrm{BCPs}$ were $\mathrm{NH}_{4}^{+}, \mathrm{K}^{+}$, and $\mathrm{Ca}^{2+}$, and the major anionic species were $\mathrm{SO}_{4}^{2-}, \mathrm{Cl}^{-}$, and $\mathrm{C}_{2} \mathrm{O}_{4}^{2-}$. The herbal BCPs had high contents of $\mathrm{K}^{+}, \mathrm{C}_{2} \mathrm{O}_{4}^{2-}$, and $\mathrm{Cl}^{-}$, while the soot had high content of $\mathrm{SO}_{4}^{2-}$.

The Brunauer-Emmett-Teller (BET) specific surface area and total porosity measured by $\mathrm{N}_{2}$ adsorption are also summarized in Table 1. A huge disparity of specific surface area was shown among the $15 \mathrm{BCPs}$ and among the BCPs within each category, ranging from 6 to $200 \mathrm{~m}^{2} \mathrm{~g}^{-1}$ for the soot, from 60 to $110 \mathrm{~m}^{2} \mathrm{~g}^{-1}$ for the woody BCPs, and from 0.1 to $52 \mathrm{~m}^{2} \mathrm{~g}^{-1}$ for the herbal BCPs. The micro- and mesoporosity of the 15 tested BCPs are summarized in Table S4. The herbal BCPs and woody BCPs were dominated by micropores (pore size $<2 \mathrm{~nm}$ ), which accounted for more than $50 \%$ of the total pore volume. Alternatively, mesopores
( $50 \mathrm{~nm}>$ pore size $>2 \mathrm{~nm}$ ) were the main pore structure of the soot, accounting for more than $61 \%$ of the total pore volume.

\subsection{Hygroscopic properties of BCPs}

Equilibrium water uptake. Figure 1 displays sorption and desorption isotherms of water vapor with BCPs plotted as equilibrium water uptake $\left(\mathrm{mg} \mathrm{g}^{-1}\right)$ by unit mass of BCPs under continuous-stepwise water vapor pressure conditions. Figure S5 displays the equilibrium sorption isotherms at selected humidity levels obtained by using saturated aqueous salt solutions. Under similar humidity conditions $(80 \%$ and $84 \%$ ), the water uptake by the 15 BCPs was very close between these two humidity regulation methods (Fig. S6), reflecting their technical validity. The woody BCPs showed very different sorption isotherm patterns from the herbal BCPs and soot. First, the water sorbing ability of the woody BCPs was much lower. The maximum water uptake observed at the highest RH (94\%) was approximately $65 \mathrm{mg} \mathrm{g}^{-1}$ by the woody BCPs but was more than $400 \mathrm{mg} \mathrm{g}^{-1}$ for the strongest sorbing herbal BCPs and soot. Second, much larger water-uptake disparities were observed within the group of herbal BCPs and the soot group than within the group of woody BCPs. Additionally, over the examined RH range (10\%-94\%), the water uptake by the woody BCPs increased slowly and linearly with the RH; however, for the herbal BCPs and soot, the water uptake increased more rapidly 
with the RH, especially under high humidity conditions $(\mathrm{RH}>70 \%)$.

To better understand the underlying mechanisms and factors controlling the hygroscopic properties of BCPs, linear relationships were built between the equilibrium water uptake and a wide variety of compositional and pore property parameters of the whole group of BCPs. Figure 2 displays regression relationships with contents of $\mathrm{OC}_{\mathrm{TGA}}, \mathrm{OC}_{\mathrm{AE}}, \mathrm{EC}$, dissolved minerals, major ionic species $\left(\mathrm{NH}_{4}^{+}, \mathrm{Cl}^{-}, \mathrm{SO}_{4}^{2-}\right.$, and $\mathrm{C}_{2} \mathrm{O}_{4}^{2-}$ ), and total porosity at $94 \% \mathrm{RH}$. The regression relationships at $23 \% \mathrm{RH}$ are presented in Fig. S7. The regression accuracy $\left(R^{2}\right.$ and $\left.P\right)$ values at the seven different RH levels $(23 \%, 33 \%, 43 \%, 47 \%, 75 \%, 84 \%, 94 \%)$ are summarized in Table S8. Good positive correlations existed between the water uptake and the contents of $\mathrm{OC}_{\mathrm{TGA}}$, $\mathrm{OC}_{\mathrm{AE}}$, and dissolved minerals under high humidity conditions (Fig. 2a, b, d). The highest regression accuracy values obtained were $R^{2}=0.82$ and $P<0.0001$ for $\mathrm{OC}_{\mathrm{TGA}}$ at $84 \% \mathrm{RH}, R^{2}=0.80$ and $P=0.001$ for $\mathrm{OC}_{\mathrm{AE}}$ at $94 \% \mathrm{RH}$, and $R^{2}=0.86$ and $P=0.0001$ for dissolved minerals at $94 \%$ RH. However, the correlations with these constituents became much weaker under low humidity conditions $\left(R^{2}=\right.$ $0.10-0.32, P=0.247-0.028$ at $\mathrm{RH}=23 \%$ ). It can be concluded that the hygroscopicity of herbal BCPs and soot under high humidity conditions was mainly controlled by the contents of $\mathrm{OC}$ and dissolved minerals. On the other hand, the low water sorbing ability of the woody BCPs was due to the very low contents of these constituents. As indicated by the elemental analysis results (Table S2), the OC constituents in the three representative BCPs (grass, red pine, and household soot) contained large amounts of oxygen-containing groups, which expectedly had very high hygroscopicity (Xiao et al., 2013). The very strong water retention ability of dissolved minerals in BCPs was understandable due to the strong hydration of mineral surfaces and ionic constituents. No correlation was observed between the water uptake of BCPs and the total organic carbon content within the whole examined RH range. Notably, a negative correlation was observed with the EC content (Fig. 2c), especially under high humidity conditions $\left(R^{2}=0.54, P=0.0019\right.$ at $\left.94 \% \mathrm{RH}\right)$. Compared with the OC in BCPs, the EC was comprised mainly of hydrophobic fused aromatic hydrocarbons and had much lower amounts of oxygen-containing groups, resulting in the very low water sorbing ability.

The above one-factor linear correlation analysis indicted that at high RH the hygroscopicity of BCPs was dominated by $\mathrm{OC}$ and dissolved minerals. Consistently, a better positive correlation $\left(R^{2}=0.90, P<0.0001\right)$ could be obtained between the equilibrium water uptake and the contents of $\mathrm{OC}_{\mathrm{TGA}}$ and dissolved mineral by binary linear regression for the tested group of BCPs (Fig. S8). Interestingly, the correlation relationship became poorer as the $\mathrm{RH}$ level gradually decreased, and the worst correlation was shown at $23 \% \mathrm{RH}$ $\left(R^{2}=0.21, P=0.028\right)$. The results suggested that the hy- groscopicity of BCPs at low RH was controlled by different factors.

At $94 \% \mathrm{RH}$, relatively good positive correlations were observed with $\mathrm{NH}_{4}^{+}$and $\mathrm{Cl}^{-}\left(R^{2}=0.50-0.70, P=0.0001-\right.$ $0.0034)$ but not with $\mathrm{SO}_{4}^{2-}\left(R^{2}=0.24, P=0.06\right)$ or $\mathrm{C}_{2} \mathrm{O}_{4}^{2-}$ $\left(R^{2}=0.002, P=0.89\right)$ (Fig. 2e-h). No correlation $\left(R^{2}=\right.$ $0.08, P=0.30$ ) was observed with the total porosity of BCPs at $94 \%$ RH (Fig. 2i). Consistently, previous studies reported that chloride salts in biomass burning aerosols had high hygroscopicity (Jing et al., 2017; Posfai et al., 2003). The poor correlation observed for $\mathrm{SO}_{4}^{2-}$ was ascribed to the low hygroscopicity of $\mathrm{CaSO}_{4}$ and $\mathrm{K}_{2} \mathrm{SO}_{4}$, as evidenced by their very high deliquescent relative humidity (96\%-97\%) (Freney et al., 2007; Preturlan et al., 2019). It is noteworthy that the content of $\mathrm{SO}_{4}^{2-}$ positively correlated with the contents of $\mathrm{Ca}^{2+}$ $\left(R^{2}=0.74, P<0.0001\right)$ and $\mathrm{K}^{+}\left(R^{2}=0.69, P=0.0008\right)$ for the tested BCPs. On the other hand, the poor correlation observed for $\mathrm{C}_{2} \mathrm{O}_{4}^{2-}$ was likely due to the formation of less water-soluble compounds (e.g., $\mathrm{CaC}_{2} \mathrm{O}_{4}$ and $\mathrm{H}_{2} \mathrm{C}_{2} \mathrm{O}_{4}$ ) that might depress the hygroscopicity (Ma et al., 2013).

The positive correlations observed with $\mathrm{NH}_{4}^{+}$and $\mathrm{Cl}^{-}$ at $94 \% \mathrm{RH}$ disappeared at $23 \% \mathrm{RH}$. Alternatively, a relatively good negative correlation $\left(R^{2}=0.42, P=0.0095\right)$ with the total porosity was shown at $23 \% \mathrm{RH}$ (Fig. S7i). Similarly, a weak negative correlation $\left(R^{2}=0.21, P=0.083\right)$ was shown with the EC content at $23 \% \mathrm{RH}$. The consistency between the total porosity and the EC content was likely due to the dominant role of graphitized carbons (EC) in forming rigid pore structures of BCPs (Han et al., 2014). On the contrary, a weak positive correlation $\left(R^{2}=0.32, P=0.028\right)$ was observed between the water uptake and the $\mathrm{OC}_{\mathrm{TGA}}$ content at $23 \% \mathrm{RH}$, indicating that the $\mathrm{OC}$ constituents were an important factor contributing to the overall water uptake by BCPs under low humidity conditions.

As can be seen from the sorption-desorption isotherms in Fig. 1, some herbal BCPs (amaranth, peanuts, wheat, millet, pea, and sorghum) and soot (diesel engine soot and household soot) showed a strong hysteresis effect (irreversible sorption), whereas none of the woody BCPs showed a hysteresis effect. Irreversible sorption would lower the release of sorbed water molecules from BCPs in the atmosphere when the RH changes from a high level to a low level. The observed hysteresis effect of herbal BCPs and soot likely stemmed from their relatively high contents of OC and/or dissolved minerals (such as wheat and household soot). Sorbing water molecules could cause strong and irreversible hydration of organic acids (Petters et al., 2017) and dissolution or phase change of minerals (Adapa et al., 2018), consequently leading to hysteresis effect due to nonidentical structures of BCPs between the sorption and desorption branches even at the same RH. The negligible hysteresis effect observed on the two woody BCPs could be attributed to their very low contents of $\mathrm{OC}$ and dissolved minerals. 

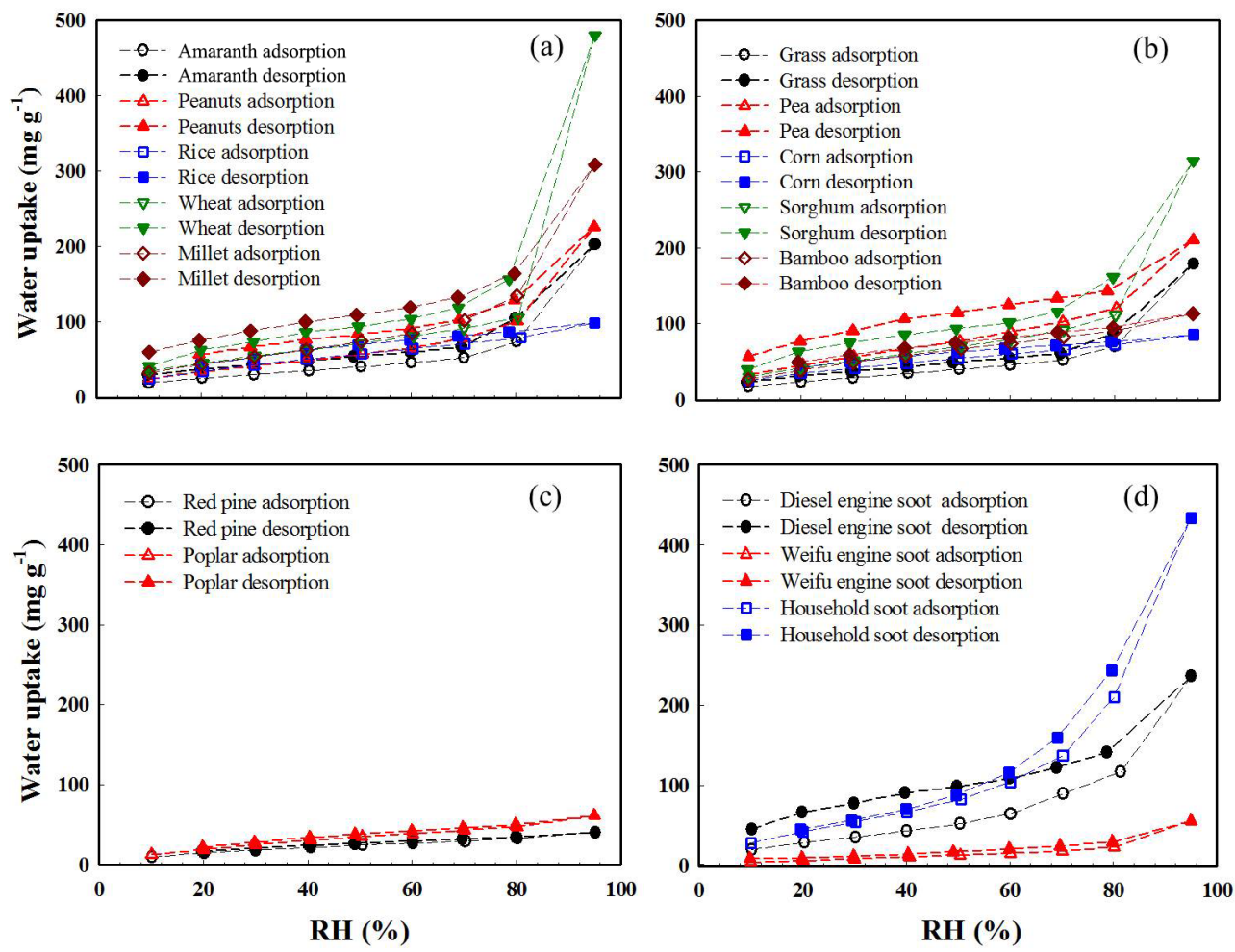

Figure 1. Sorption and desorption isotherms of water vapor plotted as water uptake $\left(\mathrm{mg} \mathrm{g}^{-1}\right)$ vs. relative humidity (RH, \%) at equilibrium for different BCPs. (a) Subgroup 1 of herbal BCPs. (b) Subgroup 2 of herbal BCPs. (c) Woody BCPs. (d) Soot. Data were collected from single-point measurements.

The equilibrium water uptake by BCPs was further investigated by DRIFTS. The spectra of representative BCPs (grass, red pine, and household soot) at varying RH are presented in Fig. 3a-c. Figure 3d compares the water uptake at $23 \% \mathrm{RH}$ monitored by the integrated intensity of the $\mathrm{O}-\mathrm{H}$ stretching region from 2750 to $3660 \mathrm{~cm}^{-1}$ (Ghorai et al., 2011), along with the water uptake measured by the multistation gravimetric method for eight selected BCPs. The identified bands of sorbed water molecules included a combination mode of symmetric stretch around $3423 \mathrm{~cm}^{-1}$ and asymmetric stretch stretch around $3253 \mathrm{~cm}^{-1}$ (Gustafsson et al., 2005). The broad feature peak centered at $2100 \mathrm{~cm}^{-1}$ was assigned to a combined band of bending, libration, and hindered translation modes of water, while the peak centered at $1640 \mathrm{~cm}^{-1}$ was attributed to the bending mode of water (Ma et al., 2010). The intensities of these peaks/bands increased with increasing RH. As assessed by the integrated intensity of the $\mathrm{O}-\mathrm{H}$ stretching region (see insets in Fig. $3 \mathrm{a}-\mathrm{c}$ ), the water uptake by grass and household soot increased gradually with RH from $12 \%$ to $80 \%$; however, the water uptake by red pine rapidly reached saturation at about $28 \% \mathrm{RH}$ and kept constant when the RH was further increased. With the exception of Weifu diesel soot, the disparity pattern of water uptake by the eight selected BCPs at $23 \% \mathrm{RH}$ monitored by DRIFTS was similar to that monitored by the multi- station gravimetric method (Fig. 3d). However, the disparities were very large between these two methods at $80 \% \mathrm{RH}$ (Fig. S9), which was probably because the saturated effect encountered in detection of sorbed water molecules by FTIR (Gustafsson et al., 2005) became worse under high humidity conditions. Moreover, the DRIFTS signals of sorbed water molecules might be influenced by the distribution of sorption sites (e.g., minerals vs. OC and exterior vs. interior), and the caused effects might lead to larger deviations under high humidity conditions.

Kinetic water uptake. Figure 4 displays the water vapor sorption kinetics to the $15 \mathrm{BCPs}$ at $94 \% \mathrm{RH}$ obtained by saturated aqueous salt solutions. The sorption kinetics at $33 \% \mathrm{RH}$ are presented in Fig. S10. The two woody BCPs exhibited similar kinetics curves; however, the herbal BCPs and soot showed very different kinetic patterns within each group. The kinetic data were fitted to the pseudo-first-order and pseudo-second-order models, $\mathrm{d} q_{t} / \mathrm{d} t=k_{1}\left(q_{\mathrm{e}}-q_{t}\right)$ and $\mathrm{d} q_{t} / \mathrm{d} t=k_{2}\left(q_{\mathrm{e}}-q_{t}\right)^{2}$, respectively, where $q_{t}$ was the sorbed concentration at time $t, q_{\mathrm{e}}$ was the equilibrium sorbed concentration, and $k_{1}$ and $k_{2}$ were the pseudo-first-order and pseudo-second-order rate constants, respectively. Note that these two kinetic models were applied only for quantitative comparison of apparent sorption kinetics among different BCPs but not for illustration of sorption mechanisms. The 

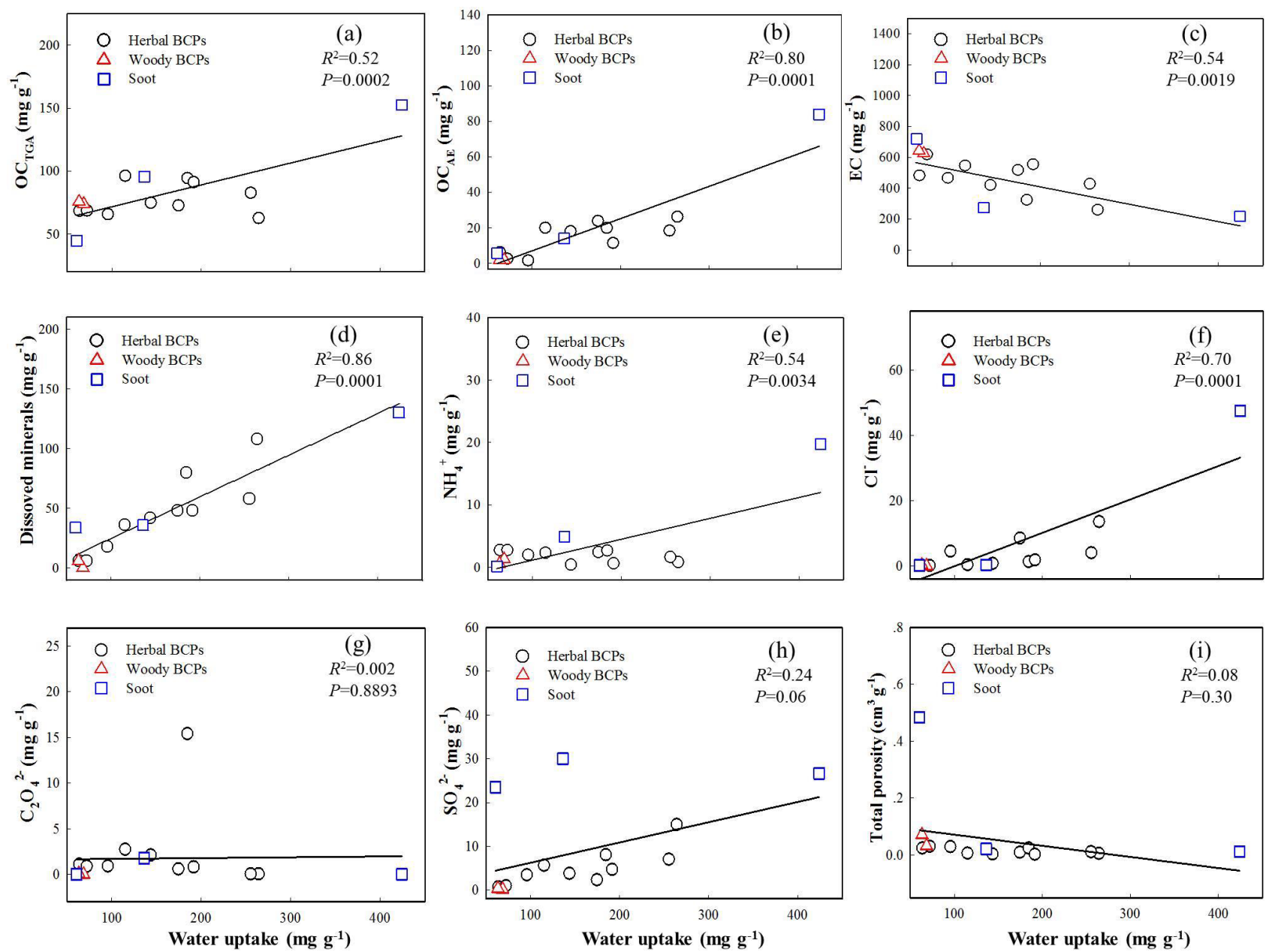

Figure 2. Relationships between equilibrium water uptake $\left(\mathrm{mg} \mathrm{g}^{-1}\right)$ vs. compositional and pore property parameters for the group of BCPs at $94 \%$ relative humidity. (a) TGA-measured organic carbon $\left(\mathrm{OC}_{\mathrm{TGA}}\right)$. (b) Alkali-extracted organic carbon $\left(\mathrm{OC}_{\mathrm{AE}}\right)$. (c) Elemental carbon (EC). (d) Dissolved minerals. (e) Ammonium $\left(\mathrm{NH}_{4}^{+}\right)$. (f) Chloride $\left(\mathrm{Cl}^{-}\right)$. (g) Oxalate $\left(\mathrm{C}_{2} \mathrm{O}_{4}^{2-}\right)$. (h) Sulfate $\left(\mathrm{SO}_{4}^{2-}\right)$. (i) Total porosity.

fitting parameters $\left(q_{\mathrm{e}}, k_{1}, k_{2}\right)$ for the three selected RH levels $(33 \%, 47 \%$, and $94 \%)$ are summarized in Tables S9-S10. The pseudo-second-order model $\left(R^{2}>0.97\right)$ fits the data better than the pseudo-first-order model $\left(R^{2}=0.80-0.99\right)$. The calculated $k_{2}$ differed greatly among the BCPs within the group of herbal BCPs and the soot group but was very close between the two woody BCPs. For a given BCPs, the $k_{2}$ at a lower RH level was significantly larger than that at a higher RH level. Similar results were reported in previous studies on sorption kinetics of water vapor to activated carbon (Ohba and Kaneko, 2011; Ribeiro et al., 2008). Under low humidity conditions, sorption of water vapor mainly occurs at the active, high-energy binding sites, and the sorption kinetics is fast; alternatively, under high humidity conditions, sorption is governed by the slow pore-filling/condensation process of water molecules within the pores of activated carbon via formation of water clusters around the water molecules already sorbed at the active sites (Nguyen and Bhatia, 2011; Rosas et al., 2008). Due to the small molecular size $(0.0958 \mathrm{~nm} \times$ $0.151 \mathrm{~nm}$, ChemDraw 3D), water molecules could well penetrate into the micropores of BCPs and form water clusters via intermolecular hydrogen bonding. The sorbing ability order of the different types of BCPs varied depending on the examined RH. At $33 \% \mathrm{RH}$, the $k_{2}$ roughly followed a decreasing order of soot $\left(0.5-5.25 \times 10^{-5} \mathrm{~g} \mathrm{mg}^{-1} \mathrm{~s}^{-1}\right)>$ woody BCPs $\left(1.57-1.90 \times 10^{-5} \mathrm{~g} \mathrm{mg}^{-1} \mathrm{~s}^{-1}\right)>$ herbal BCPs $(0.34-2.07 \times$ $10^{-5} \mathrm{~g} \mathrm{mg}^{-1} \mathrm{~s}^{-1}$ ); however, no clear trend was shown for high humidity conditions (e.g., $\mathrm{RH}=94 \%$ ), mainly resulting from the larger variances within the group of herbal BCPs and soot group.

Like for the equilibrium water uptake, the relationships were built between the $k_{2}$ and the contents of $\mathrm{OC}_{\mathrm{TGA}}, \mathrm{OC}_{\mathrm{AE}}$, $\mathrm{EC}$, dissolved minerals, major ionic species $\left(\mathrm{NH}_{4}^{+}, \mathrm{Cl}^{-}\right.$, $\mathrm{C}_{2} \mathrm{O}_{4}^{2-}$ and $\mathrm{SO}_{4}^{2-}$ ), and total porosity at $94 \% \mathrm{RH}$ (Fig. 5). The regression relationships at $33 \% \mathrm{RH}$ are presented in Fig. S11. The regression accuracy $\left(R^{2}\right.$ and $\left.P\right)$ values at 

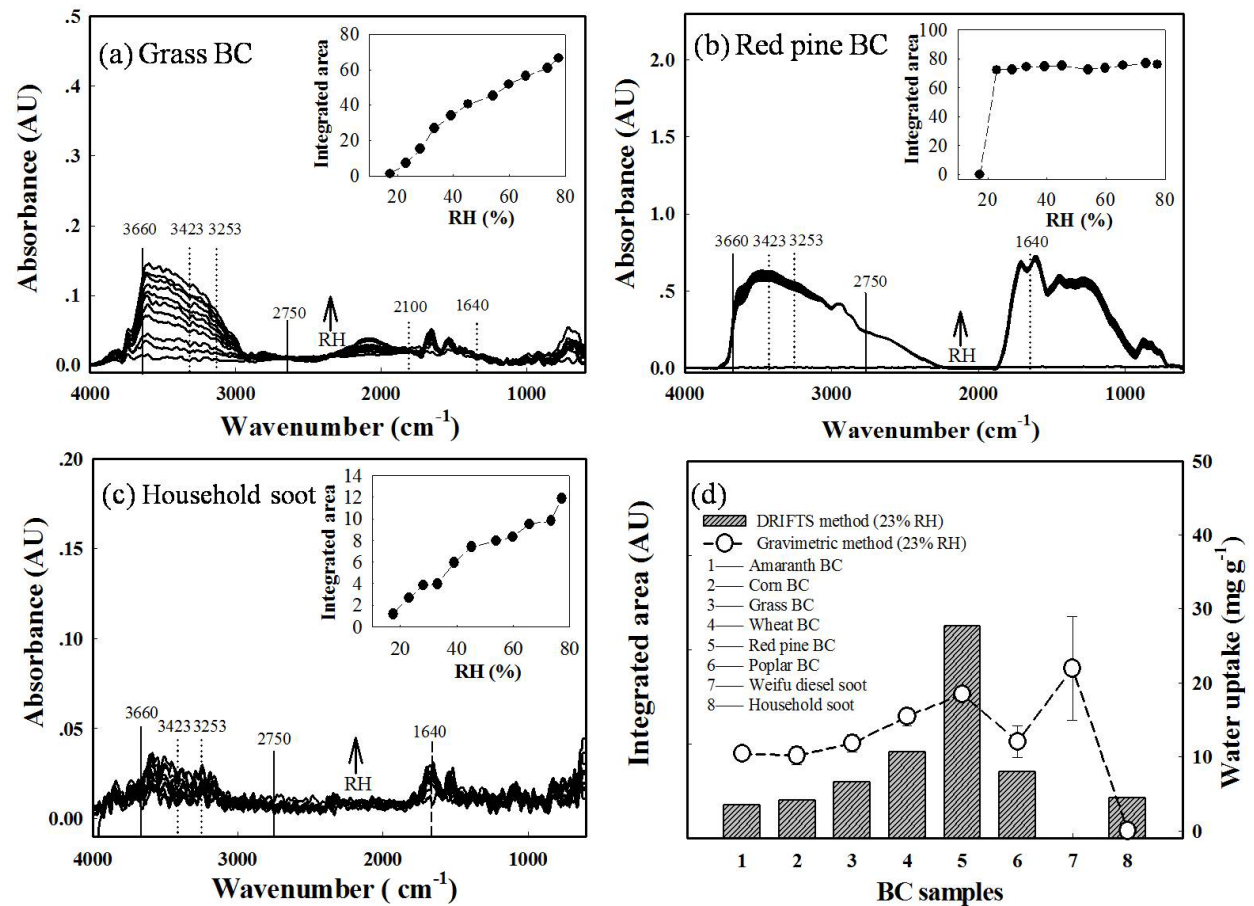

Figure 3. Diffuse reflectance infrared Fourier transform spectroscopy (DRIFTS) characterization of equilibrium water uptake by BCPs. (a-c) Spectra for the three representative BCPs (grass, red pine, and household soot) equilibrated at varying relative humidity (RH) levels. (d) Comparison of equilibrium water uptake measured as integrated area of $\mathrm{O}-\mathrm{H}$ stretching region $\left(2750-3660 \mathrm{~cm}^{-1}\right)$ between eight selected BCPs at $23 \%$ relative humidity. Error bars represent standard variations from duplicate samples. Insets in panels (a-c) present water uptake measured as integrated area of $\mathrm{O}-\mathrm{H}$ stretching region against $\mathrm{RH}$.
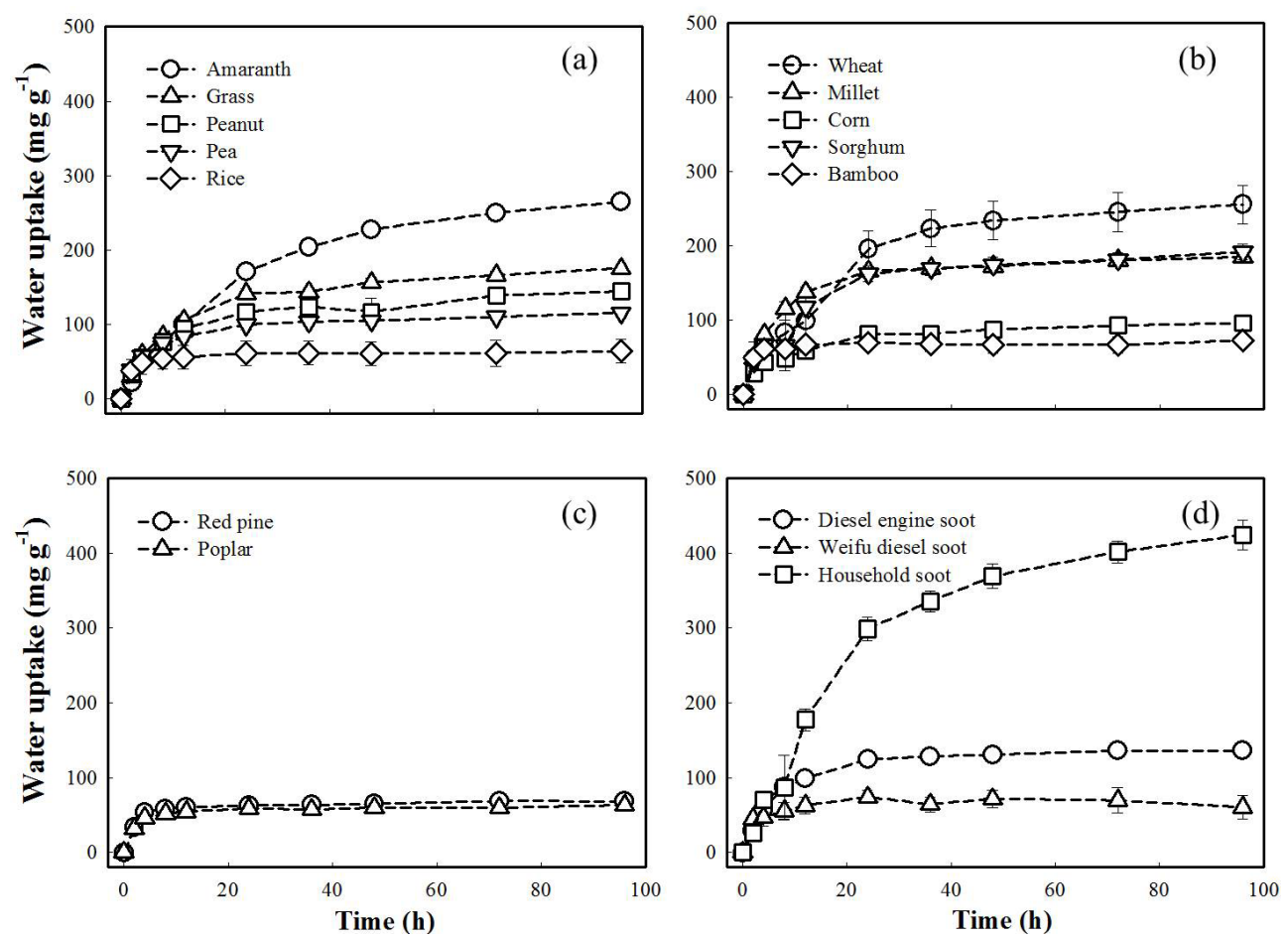

Figure 4. Sorption kinetics of water vapor plotted as water uptake $\left(\mathrm{mg} \mathrm{g}^{-1}\right)$ vs. time (h) at $94 \%$ relative humidity. (a) Subgroup 1 of herbal BCPs. (b) Subgroup 2 of herbal BCPs. (c) Woody BCPs. (d) Soot. Error bars represent standard variations from duplicate samples. 

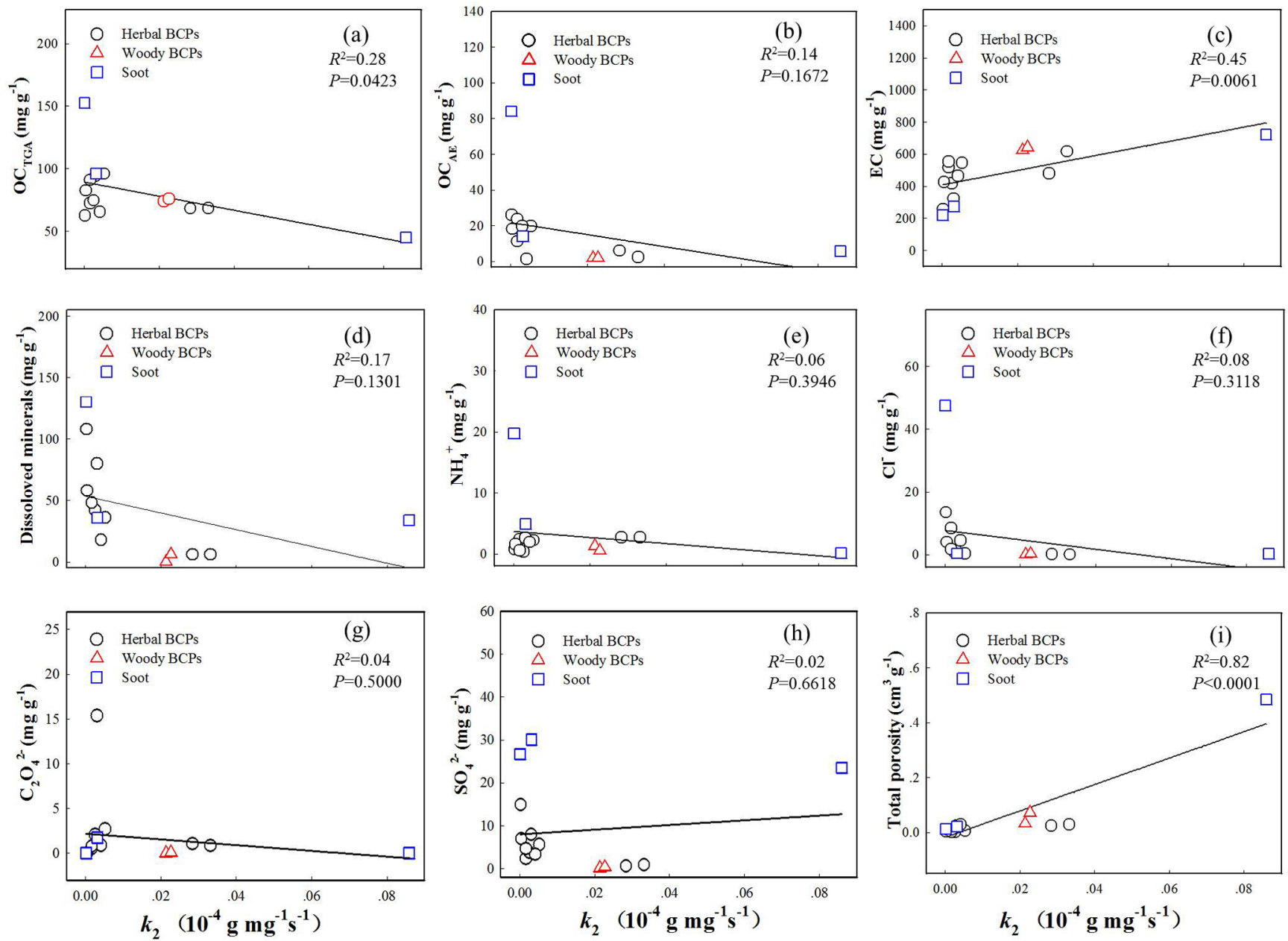

Figure 5. Relationships between pseudo-second-order water uptake rate constant $\left(k_{2}\right)\left(\mathrm{g} \mathrm{mg}^{-1} \mathrm{~s}^{-1}\right)$ vs. compositional and pore property parameters for the group of BCPs at $94 \%$ relative humidity. (a) TGA-measured organic carbon $\left(\mathrm{OC}_{\mathrm{TGA}}\right)$. (b) Alkali-extracted organic carbon $\left(\mathrm{OC}_{\mathrm{AE}}\right)$. (c) Elemental carbon (EC). (d) Dissolved minerals. (e) Ammonium $\left(\mathrm{NH}_{4}^{+}\right)$. (f) Chloride $\left(\mathrm{Cl}^{-}\right)$. (g) $\mathrm{Oxalate}\left(\mathrm{C}_{2} \mathrm{O}_{4}^{2-}\right)$. (h) Sulfate $\left(\mathrm{SO}_{4}^{2-}\right)$. (i) Total porosity.

$33 \%, 47 \%$, and $94 \%$ RH are summarized in Table S11. At $94 \% \mathrm{RH}$, a strong positive correlation was observed between the $k_{2}$ and the total porosity $\left(R^{2}=0.82, P<0.0001\right)$, likely resulting from the pore-filling/condensation mechanism. A similar mechanism has been previously proposed to account for the positive correlation observed between the water vapor sorption kinetics and the porosity of activated carbon under high humidity conditions (Nakamura et al., 2010; Velasco et al., 2016). Likewise, a positive correlation $\left(R^{2}=0.45, P=0.0061\right)$ was observed between the $k_{2}$ and the EC content, which could be ascribed to the formation of rigid pore structures dominantly by graphitized carbons (EC) (Han et al., 2014). The correlation between $k_{2}$ and total porosity observed at $94 \% \mathrm{RH}$ disappeared under low and medium humidity conditions. At $33 \% \mathrm{RH}$, relatively good positive correlations were observed with the contents of $\mathrm{OC}_{\mathrm{TGA}}\left(R^{2}=0.47, P=0.0046\right), \mathrm{OC}_{\mathrm{AE}}\left(R^{2}=0.44, P=\right.$
$0.007), \mathrm{NH}_{4}^{+}\left(R^{2}=0.77, P<0.0001\right)$, and $\mathrm{Cl}^{-}\left(R^{2}=0.60\right.$, $P=0.0007)$ but not with $\mathrm{SO}^{2-}\left(R^{2}=0.11, P=0.2286\right)$ or dissolved minerals $\left(R^{2}=0.08, P=0.31\right)$. The positive correlations with these constituents were not shown under medium and high humidity conditions. Thus, the constituents of $\mathrm{OC}$ and $\mathrm{NH}_{4}^{+}$and $\mathrm{Cl}^{-}$salts likely provided the primary high-affinity active sites for sorption of water vapor under low humidity conditions.

\section{Conclusions}

The hygroscopic properties of 15 different BCPs (herbal, woody, and soot) were systematically investigated using a gravimetric method and DRIFTS. The mechanisms and factors controlling the equilibrium and kinetic water uptake differed among the types of BCPs and depended heavily on the humidity conditions. Linear correlation analyses indi- 
cated that the equilibrium water uptake by the tested group of BCPs positively correlated to the contents of $\mathrm{OC}\left(\mathrm{OC}_{\mathrm{TGA}}\right.$ and $\mathrm{OC}_{\mathrm{AE}}$ ), dissolved minerals, and $\mathrm{NH}_{4}^{+}$and $\mathrm{Cl}^{-}$salts under high humidity conditions and weakly to the contents of OC only under low humidity conditions. By contrast, negative correlations were observed between the equilibrium water uptake and the EC content. The low water uptake by the woody BCPs could be attributed to the very low contents of $\mathrm{OC}$ and dissolved minerals. Thus, the equilibrium water uptake by BCPs was mainly controlled by the hygroscopic constituents of $\mathrm{OC}$ and dissolved minerals or salts. The kinetic water uptake by the BCPs could be well described by the pseudo-second-order kinetic model. The calculated rate constant $\left(k_{2}\right)$ positively correlated to the contents of $\mathrm{OC}_{\mathrm{TGA}}$, $\mathrm{OC}_{\mathrm{AE}}$, and $\mathrm{NH}_{4}^{+}$and $\mathrm{Cl}^{-}$salts under low humidity conditions and to the total porosity only under high humidity conditions. The fast water uptake kinetics under low humidity conditions was attributed to the binding to high-affinity active sites (OC and salts), which could sorb water vapor fast but had limited contents. Alternatively, the slow water uptake kinetics under high humidity conditions was attributed to pore-filling and condensation of water molecules within the micro- and mesopores of BCPs. This study highlights that the hygroscopic properties of BCPs rely on compositional and structural properties of BCPs as well as humidity conditions.

Data availability. The underlying research data used in this study are available. Readers can access the data directly in the article and the Supplement or by contacting Dongqiang Zhu via zhud@pku.edu.cn.

Supplement. The supplement related to this article is available online at: https://doi.org/10.5194/acp-20-7941-2020-supplement.

Author contributions. DZ provided the original idea and prepared the paper with contributions from all co-authors. MW and YC designed and conducted the research, and HF and XQ were involved in the development of the analysis methods. BL and ST reviewed the written document.

Competing interests. The authors declare that they have no conflict of interest.

Acknowledgements. This work was supported by the National Natural Science Foundation of China (grant nos. 21777002, 21920102002, and 41991331).
Financial support. This research has been supported by the National Natural Science Foundation of China (grant nos. 21777002, 21920102002, 41991331).

Review statement. This paper was edited by Anne Perring and reviewed by two anonymous referees. 


\section{Appendix A}

Detailed characterization results of the different BCPs can be found in Tables S1-S7. Table S8 lists accuracy $\left(R^{2}\right.$ and $\left.P\right)$ values for regression on equilibrium water uptake against different variables. Tables S9-S10 present pseudo-first/secondorder kinetic model fitting parameters. Table S11 lists accuracy $\left(R^{2}\right.$ and $P$ ) values for regression on $k_{2}$ against different variables. Figures S1-S4 displays spectroscopic characterization of different BCPs. Figure S5 displays sorption isotherms at selected humidity obtained by using saturated aqueous salt solutions. Figure S6 compares equilibrium water uptake measured by the two different gravimetric methods. Figure S7 displays relationships between equilibrium water uptake and different variables at $23 \%$ RH. Figure S8 displays the relationship between measured values of equilibrium water uptake at $94 \%$ relative humidity vs. predicted values obtained by binary factor regression based on contents of $\mathrm{OC}_{\mathrm{TGA}}$ and dissolved minerals for the group of BCPs. Figure S9 compares equilibrium water uptake measured by DRIFTS and gravimetric method at high RH. Figure S10 displays sorption kinetics of water uptake at $33 \% \mathrm{RH}$. Figure S11 displays relationships between $k_{2}$ and different variables at $33 \% \mathrm{RH}$. 


\section{References}

Adapa, S., Swamy, D. R., Kancharla, S., Pradhan, S., and Malani, A.: Role of mono- and divalent surface cations on the structure and adsorption behavior of water on mica surface, Langmuir, 34, 14472-14488, https://doi.org/10.1021/acs.langmuir.8b01128, 2018.

Andreae, M. O. and Gelencsér, A.: Black carbon or brown carbon? The nature of light-absorbing carbonaceous aerosols, Atmos. Chem. Phys., 6, 3131-3148, https://doi.org/10.5194/acp-63131-2006, 2006.

Archanjo, B. S., Araujo, J. R., Silva, A. M., Capaz, R. B., Falcao, N. P. S., Jorio, A., and Achete, C. A.: Chemical analysis and molecular models for calcium-oxygen-carbon interactions in black carbon found in fertile Amazonian anthrosoils, Environ. Sci. Technol., 48, 7445-7452, 2014.

Bond, T. C., Doherty, S. J., Fahey, D. W., Forster, P. M., Berntsen, T., DeAngelo, B. J., Flanner, M. G., Ghan, S., Kärcher, B., Koch, D., Kinne, S., Kondo, Y., Quinn, P. K., Sarofim, M. C., Schultz, M. G., Schulz, M., Venkataraman, C., Zhang, H., Zhang, S., Bellouin, N., Guttikunda, S. K., Hopke, P. K., Jacobson, M. Z., Kaiser, J. W., Klimont, Z., Lohmann, U., Schwarz, J. P., Shindell, D., Storelvmo, T., Warren, S. G., and Zender, C. S.: Bounding the role of black carbon in the climate system: A scientific assessment, J. Geophys. Res.-Atmos., 118, 5380-5552, 2013.

Cancado, L. G., Takai, K., Enoki, T., Endo, M., Kim, Y. A., and Mizusaki, H.: General equation for the determination of the crystallite size L-a of nanographite by Raman spectroscopy, Appl. Phys. Lett., 88, 163106, https://doi.org/10.1063/1.2196057, 2006

Carrico, C. M., Petters, M. D., Kreidenweis, S. M., Sullivan, A. P., McMeeking, G. R., Levin, E. J. T., Engling, G., Malm, W. C., and Collett Jr., J. L.: Water uptake and chemical composition of fresh aerosols generated in open burning of biomass, Atmos. Chem. Phys., 10, 5165-5178, https://doi.org/10.5194/acp10-5165-2010, 2010.

Day, D. E., Hand, J. L., Carrico, C. M., Engling, G., and Malm, W. C.: Humidification factors from laboratory studies of fresh smoke from biomass fuels, J. Geophys. Res., 111, D22202, https://doi.org/10.1029/2006JD007221, 2006.

Fletcher, A. J., Uygur, Y., and Mark Thomas, K.: Role of surface functional groups in the adsorption kinetics of water vapor on microporous activated carbons, J. Phys. Chem. C., 111, 83498359, 2007.

Freney, E. J., Martin, S. T., and Buseck, P. R.: Deliquescence measurements of potassium salts, American Geophysical Union, Fall Meeting, December, abstract id. A23B-1255, 2007.

Ghorai, S., Laskin, A., and Tivanski, A. V.: Spectroscopic evidence of keto-enol tautomerism in deliquesced malonic acid particles, J. Phys. Chem. A., 115, 4373-4380, 2011.

Gu, W., Li, Y., Zhu, J., Jia, X., Lin, Q., Zhang, G., Ding, X., Song, W., Bi, X., Wang, X., and Tang, M.: Investigation of water adsorption and hygroscopicity of atmospherically relevant particles using a commercial vapor sorption analyzer, Atmos. Meas. Tech., 10, 3821-3832, https://doi.org/10.5194/amt10-3821-2017, 2017.

Gustafsson, R. J., Orlov, A., Badger, C. L., Griffiths, P. T., Cox, R. A., and Lambert, R. M.: A comprehensive evaluation of water uptake on atmospherically relevant mineral surfaces: DRIFT spectroscopy, thermogravimetric analysis and aerosol growth measurements, Atmos. Chem. Phys., 5, 3415-3421, https://doi.org/10.5194/acp-5-3415-2005, 2005.

Haddrell, A. E., Davies, J. F., and Reid, J. P.: Dynamics of particle size on inhalation of environmental aerosol and impact on deposition fraction, Environ. Sci. Technol., 49, 14512-14521, 2015.

Han, C., Liu, Y., and He, H.: Role of organic carbon in heterogeneous reaction of $\mathrm{NO}_{2}$ with soot, Environ. Sci. Technol., 47, 3174-3181, 2013.

Han, L. F., Sun, K., Jin, J., Wei, X., Xia, X. H., Wu, F. C., Gao, B., and Xing, B. S.: Role of structure and microporosity in phenanthrene sorption by natural and engineered organic matter, Environ. Sci. Technol., 48, 11227-11234, 2014.

Jing, B., Peng, C., Wang, Y., Liu, Q., Tong, S., Zhang, Y., and Ge, M.: Hygroscopic properties of potassium chloride and its internal mixtures with organic compounds relevant to biomass burning aerosol particles, Sci. Rep., 2, 43573, https://doi.org/10.1038/srep43572, 2017.

Keiluweit, M., Nico, P. S., Johnson, M. G., and Kleber, M.: Dynamic molecular structure of plant biomass-derived black carbon (biochar), Environ. Sci. Technol., 44, 1247-1253, 2010.

Lewis, K. A., Arnott, W. P., Moosmüller, H., Chakrabarty, R. K., Carrico, C. M., Kreidenweis, S. M., Day, D. E., Malm, W. C., Laskin, A., Jimenez, J. L., Ulbrich, I. M., Huffman, J. A., Onasch, T. B., Trimborn, A., Liu, L., and Mishchenko, M. I.: Reduction in biomass burning aerosol light absorption upon humidification: roles of inorganically-induced hygroscopicity, particle collapse, and photoacoustic heat and mass transfer, Atmos. Chem. Phys., 9, 8949-8966, https://doi.org/10.5194/acp-9-89492009, 2009.

Li, J., Posfai, M., Hobbs, P. V., and Buseck, P. R.: Individual aerosol particles from biomass burning in southern Africa: 2. Compositions and aging of inorganic particles, J. Geophys. Res., 108, 8484, https://doi.org/10.1029/2002JD002310, 2003.

Lian, F. and Xing, B.: Black carbon (biochar) in water/soil environments: Molecular structure, sorption, stability, and potential risk, Environ. Sci. Technol., 51, 13517-13532, 2017.

Liu, P., Song, M., Zhao, T., Gunthe, S. S., Ham, S., He, Y., Qin, Y. M., Gong, Z., Amorim, J. C., Bertram, A. K., and Martin, S. T.: Resolving the mechanisms of hygroscopic growth and cloud condensation nuclei activity for organic particulate matter, Nat. Commun., 9, 4076, https://doi.org/10.1038/s41467-018-066222, 2018.

Ma, Q., He, H., and Liu, Y.: In situ DRIFTS study of hygroscopic behavior of mineral aerosol, J. Environ. Sci., 22, 555-560, 2010.

Ma, Q., He, H., and Liu, C.: Hygroscopic properties of oxalic acid and atmospherically relevant oxalates, Atmos. Environ., 69, 281288, 2013.

Matthews, H. D., Gillett, N. P., Stott, P. A., and Zickfeld, K.: The proportionality of global warming to cumulative carbon emissions, Nature, 459, 829-832, 2009.

Nakamura, M., Ohba, T., Branton, P., Kanoh, H., and Kaneko, K.: Equilibrium-time and pore width dependent hysteresis of water adsorption isotherm on hydrophobic microporous carbons, Carbon, 48, 2549-2553, 2010.

Nguyen, T. X. and Bhatia, S. K.: How water adsorbs in hydrophobic nanospaces, J. Phys. Chem. C, 115, 16606-16612, 2011.

Nienow, A. M. and Roberts, J. T.: Heterogeneous chemistry of carbon aerosols, Rev. Phys. Chem., 57, 105-128, 2006. 
Ohba, T. and Kaneko, K.: Kinetically forbidden transformations of water molecular assemblies in hydrophobic micropores, Langmuir, 27, 7609-7613, 2011.

Petters, S. S., Pagonis, D., Claflin, M. S., Levin, E. J. T., Petters, M. D., Ziemann, P. J., and Kreidenweis, S. M.: Hygroscopicity of organic compounds as a function of carbon chain length and carboxyl, hydroperoxy, and carbonyl functional groups, J. Phys. Chem. A., 121, 5164-5174, 2017.

Pimenta, M. A., Dresselhaus, G., Dresselhaus, M. S., Cancado, L. G., Jorio, A., and Saito, R.: Studying disorder in graphite-based systems by Raman spectroscopy, Phys. Chem. Chem. Phys., 9, 1276-1291, 2007.

Posfai, M., Simonics, R., Li, J., Hobbs, P. V., and Buseck, P. R.: Individual aerosol particles from biomass burning from southern Africa: 1. Compositions and size distributions of carbonaceous particles, J. Geophys. Res., 108, 8483, https://doi.org/10.1029/2002JD002291, 2003.

Powelson, M. H., Espelien, B. M., Hawkins, L. N., Galloway, M. M., and De Haan, D. O.: Brown carbon formation by aqueousphase carbonyl compound reactions with amines and ammonium sulfate, Environ. Sci. Technol., 48, 985-993, 2014.

Preturlan, J. G. D., Vieille, L., Quiligotti, S., and Favergeon, L.: Comprehensive thermodynamic study of the calcium sulfatewater vapor system. Part 1: experimental measurements and phase equilibria, Ind. Eng. Chem. Res., 58, 9596-9606, 2019.

Qiu, C., Khalizov, A. F., and Zhang, R.: Soot aging from $\mathrm{OH}-$ Initiated oxidation of toluene, Environ. Sci. Technol., 46, 94649472, 2012.

Reid, J. S., Koppmann, R., Eck, T. F., and Eleuterio, D. P.: A review of biomass burning emissions part II: intensive physical properties of biomass burning particles, Atmos. Chem. Phys., 5, 799825, https://doi.org/10.5194/acp-5-799-2005, 2005.

Ribeiro, A. M., Sauer, T. P., Grande, C. A., Moreira, R. F. P. M., Loureiro, J. M., and Rodrigues, A. E.: Adsorption equilibrium and kinetics of water vapor on different adsorbents, Ind. Eng. Chem. Res., 47, 7019-7026, 2008.

Rosas, J. M., Bedia, J., Miraso, J. R., and Cordero, T.: Preparation of hemp-derived activated carbon monoliths, adsorption of water vapor, Ind. Eng. Chem. Res., 47, 1288-1296, 2008.

Schwarz, J. P., Spackman, J. R., Fahey, D. W., Gao, R. S., Lohmann, U., Stier, P., Watts, L. A., Thomson, D. S., Lack, D. A., Pfister, L., Mahoney, M. J., Baumgardner, D., Wilson, J. C., and Reeves, J. M.: Coatings and their enhancement of black carbon light absorption in the tropical atmosphere, J. Geophys. Res., 113, D03203, https://doi.org/10.1029/2007JD009042, 2008.

Seisel, S., Pashkova, A., Lian, Y., and Zellner, R.: Water uptake on mineral dust and soot: a fundamental view of the hydrophilicity of atmospheric particles, Faraday Discuss., 130, 437-451, 2005.

Sjogren, S., Gysel, M., Weingartner, E., Baltensperger, U., Cubison, M. J., Coe, H., Zardini, A. A., Marcolli, C., Krieger, U. K., and Peter, T.: Hygroscopic growth and water uptake kinetics of twophase aerosol particles consisting of ammonium sulfate, adipic and humic acid mixtures, Aerosol Sci., 38, 157-171, 2007.

Song, W. and Boily, J. F.: Water vapor adsorption on goethite, Environ. Sci. Technol., 47, 7171-7177, 2013.
Song, J., Peng, P., and Huang, W.: Black carbon and kerogen in soils and sediments. 1. Quantification and characterization, Environ, Sci. Technol., 36, 3960-3967, 2002.

Stanislav, V., Vassilev, D. B., Andersen, L. K., and Vassileva, C. G.: An overview of the composition and application of biomass ash. Part 1. Phase-mineral and chemical composition and classification, Fuel, 105, 40-76, 2013.

Stemmler, K., Vlasenko, A., Guimbaud, C., and Ammann, M.: The effect of fatty acid surfactants on the uptake of nitric acid to deliquesced $\mathrm{NaCl}$ aerosol, Atmos. Chem. Phys., 8, 5127-5141, https://doi.org/10.5194/acp-8-5127-2008, 2008.

Suda, S. R., Petters, M. D., Yeh, G. K. Strollo, C., Matsunaga, A., Faulhaber, A., Ziemann, P. J., Prenni, A. J., Carrico, C. M., Sullivan, R. C., and Kreidenweis, S. M.: Influence of functional groups on organic aerosol cloud condensation nucleus activity, Environ. Sci. Technol., 48, 10182-10190, 2014.

Velasco, L. F., Remy Guillet, N. R., Dobos, G., Thommes, M., and Lodewyckx, P.: Towards a better understanding of water adsorption hysteresis in activated carbons by scanning isotherms, Carbon, 96, 753-758, 2016.

Wei, S., Zhu, M., Fan, X., Song, J., Peng, P., Li, K., Jia, W., and Song, H.: Influence of pyrolysis temperature and feedstock on carbon fractions of biochar produced from pyrolysis of rice straw, pine wood, pig manure and sewage sludge, Chemosphere, 218, 624-631, 2019.

Xiao, J., Liu, Z., Kim, K., Chen, Y., Yan, J., Li, Z., and Wang, W.: S/O-Functionalities on modified carbon materials governing adsorption of water vapor, J. Phys. Chem. C., 117, 23057-23065, 2013.

Xiao, X., Chen, B., Chen, Z., Zhu, L., and Schnoor, J. L.: Insight into multiple and multilevel structures of biochars and their potential environmental applications: A critical review, Environ. Sci. Technol., 52, 5027-5047, 2018.

Yuan, W., Li, X., Pan, Z., Connell, L. D., Li, S., and He, J.: Experimental investigation of interactions between water and a lower silurian chinese shale, Energy Fuels, 28, 4925-4933, 2014.

Yuan, J.-F., Huang, X.-F., Cao, L.-M., Cui, J., Zhu, Q., Huang, C.N., Lan, Z.-J., and He, L.-Y.: Light absorption of brown carbon aerosol in the PRD region of China, Atmos. Chem. Phys., 16, 1433-1443, https://doi.org/10.5194/acp-16-1433-2016, 2016.

Zhang, R., Khalizov, A., Wang, L., Hu. M., and Xu, W.: Nucleation and growth of nanoparticles in the atmosphere, Chem. Rev., 112, 1957-2011, 2012.

Zuend, A., Marcolli, C., Booth, A. M., Lienhard, D. M., Soonsin, V., Krieger, U. K., Topping, D. O., McFiggans, G., Peter, T., and Seinfeld, J. H.: New and extended parameterization of the thermodynamic model AIOMFAC: calculation of activity coefficients for organic-inorganic mixtures containing carboxyl, hydroxyl, carbonyl, ether, ester, alkenyl, alkyl, and aromatic functional groups, Atmos. Chem. Phys., 11, 9155-9206, https://doi.org/10.5194/acp-11-9155-2011, 2011. 